\title{
Mini grafts: alternative to obtain complete plants of Pinus patula propagated in vitro
}

\author{
Carlos Román Castillo-Martínez ${ }^{1}$; Vidal Guerra de la Gruz ${ }^{2}$; Javier López Upton ${ }^{3}$ \\ 1 Instituto Nacional de Investigaciones Forestales, Agrícolas y Pecuarias, Centro Nacional de Investigación \\ disciplinaria en Conservación y Mejoramiento de Ecosistemas Forestales, Progreso Núm. 5 Colonia Barrio \\ de Santa Catarina, Coyoacán, Ciudad de México. \\ 2 Instituto Nacional de Investigaciones Forestales, Agrícolas y Pecuarias, Centro de Investigación Regional \\ Centro (CIRCE), Carretera Celaya San Miguel Allende Km. 6.5 Celaya, Gto. C.P. 38110. \\ 3 Colegio de Postgraduados, Campus Montecillo, km 36.5 Carr. México-Texcoco, 56230, Texcoco, Estado de \\ México, México. \\ * Correspondence: uptonj@colpos.mx.
}

Gitation: Castillo-Martínez, C.R.,

Guerra de la Cruz. V., \& López-Upton, J. (2021). Mini grafts: alternative to obtain complete plants of Pinus patula propagated in vitro. Agro Productividad https://doi.org/10.32854/agrop. v14i12.2198

Editor in Chief: Dr. Jorge Cadena Iñiguez

Received: June 12, 2021.

Accepted: November 15, 2021. Published on-line: December 30, 2021.

Agro Productividad, 14(12). December. 2021. pp: 159-164.

This work is licensed under a Creative Commons Attribution-NonCommercial 4.0 International license.

\section{(1) (5)}

\begin{abstract}
Micro-grafting and mini-grafting trials were carried out in order to obtain complete Pinus patula plants generated in vitro, derived from the fact that the formation of roots in micro-propagated shoots is very low or null. On the other hand, there is the possibility of generating clones with outstanding genetic characteristics. P. patula seeds were established in aseptic conditions and geminated in vitro in DCR medium; the aerial part was dissected from the base and roots were kept in DCR medium added with $0.5 \mathrm{mg} \mathrm{l}^{-1}$ of NAA to maintain them and served as mini rootstock, the shoots were transferred to DCR medium added with $2.0 \mathrm{mg} \mathrm{l}^{-1}$ of BA to form seedlings with an average of 3.9 shoots per explant at 30 days. On the other hand, 2-month-old nursery seedlings were used as rootstock for the mini-grafts. For the micro-graft tests, the shoots obtained were taken and the apical meristems with approximately $5 \mathrm{~mm}$ were isolated to conduct micro-grafting at the base with roots, and in the case of mini-grafts the shoots generated were allowed to grow to a length of $3 \mathrm{~cm}$ on average and grafted onto nursery seedlings. In both cases, the achievement of the grafted materials and the length were evaluated to measure the growth of the materials that had positive success. The response of micro-grafts was very low, $10 \%$ success, in addition to the manipulation of the meristems being very complex, which generated oxidation in the tissues. On the contrary, the mini-grafts showed 93.3 of grafting success and average growth of $26.05 \mathrm{~cm}$, two months after the grafting process.
\end{abstract}

Key words: mini-graft, in vitro culture, micro-graft.

\section{INTRODUCTION}

In vitro propagation of plants is a very useful tool for massive propagation, breeding and conservation processes of plant species, used successfully in many herbaceous and some woody species. In conifers, responses have been reported in both organogenesis paths and in embryogenesis that have been very successful, since they guarantee generating complete plants (Atreea and Fowke, 1991; Grossnickle et al., 1996).

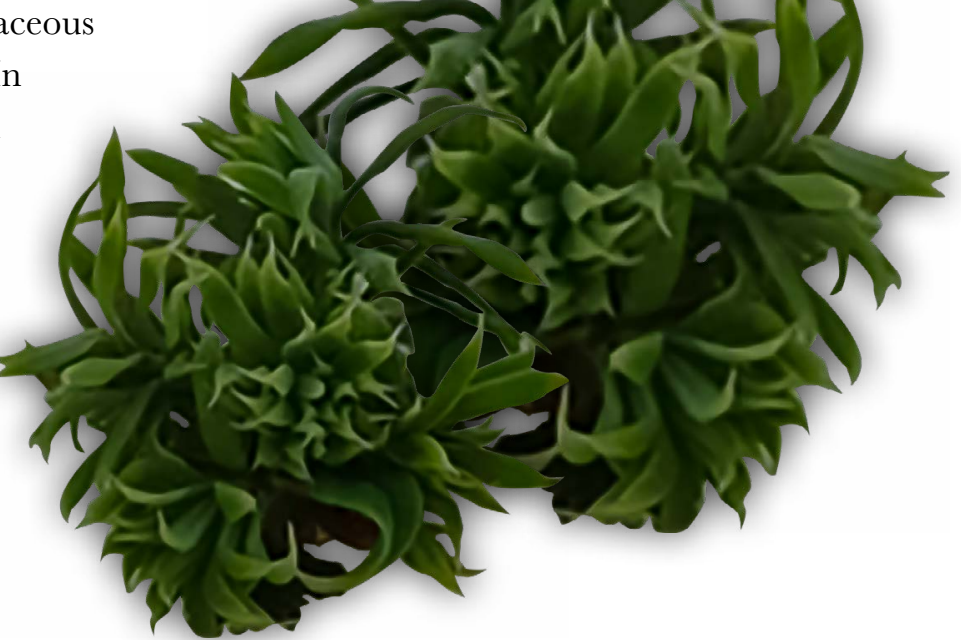


There are very few species that present favorable responses in both organogenesis paths (organogenesis and embryogenesis) as Pinus radiata (Montalbán et al., 2011; Prehn et al., 2003). On the other hand, organogenesis in conifers has generated complete plants in few species, and the low or null formation of roots has been discouraging (Thorpe, 2004); only few species have shown positive results, as is the case of $P$. radiata which has been able to be multiplied in vitro from young shoots (Prehn et al., 2003). Propagating conifers in vitro opens the possibility of generating clones from selected trees and if the initial material is somatic tissue this is possible; for this reason, techniques such as micro-grafts have been explored, and successful protocols have been generated for Pinus pinea starting from mature shoots multiplied in vitro to be micro-grafted (Cortizo et al., 2004). Another species with which studies have been performed in this regard is Pinus radiata; Fraga et al. (2002) found that in order to be successful the manipulation and quality of the micro-graft are very important. On the other hand, Oviedo et al. (2008) found that the time of the year is a defining factor that affects the success of micro-grafts. In the case of mini-grafts, this technique has been studied more in agricultural tree species such as citruses. An example of this is the research by Álvarez (2020) who evaluated terminal and inverted-T mini-grafts in Citrus sinensis; however, in forest species such as Prosopis alba the potential of this technique to produce this species in a large scale has been reported (Ewens and Felker, 2003). In this context, the aim of this study is to establish Pinus patula material in in vitro conditions, and to evaluate the grafting response both for micro- and mini-grafts.

\section{MATERIALS AND METHODS}

Biological material. The biological material used were $P$. patula seeds and nursery seedlings, in both cases from material collected in the state of Oaxaca. The seeds were germinated in vitro and the seedlings were kept in a greenhouse to be used as rootstock or understock. All the trials were carried out in the Forest Biotechnology laboratory of the National Center for Disciplinary Research in Conservation and Forest Ecosystem Improvement, located in Mexico City, Mexico. The in vitro management included four stages: Establishment in aseptic conditions and germination, Maintenance and multiplication, Rooting test, and Micro-graft tests. The mini-grafts tests are in fact, considered as ex vitro management.

Establishment in aseptic conditions and in vitro germination. The seeds were placed in a lidded tube or container with hydrogen peroxide at $3 \% \mathrm{v} / \mathrm{v}$, during $24 \mathrm{~h}$, previous to the in vitro germination. Then, the seeds were rinsed three times with sterile water to eliminate the peroxide. Following steps were carried out in a laminar flow hood, adding again hydrogen peroxide at 3\% for 15 min, which it was then eliminated. Chlorine at 20\% $\mathrm{v} / \mathrm{v}$ was added for 12 minutes, and then eliminated through 5 times-rinses with distilled sterile water. At that point, the decontamination process of the seeds ends and they were placed in the DCR medium for germination; a total of 100 seeds were used in this process.

Maintenance and multiplication of vitro plants. The culture medium proposed by Gupta and Durzan (1985) known as DCR was used, supplemented with $30 \mathrm{~g} \mathrm{l}^{-1}$ of sucrose, $1 \mathrm{gl}^{-1}$ of activated carbon, and $9.0 \mathrm{~g} \mathrm{l}^{-1}$ of agar. The $\mathrm{pH}$ was adjusted to 5.7 with a potentiometer (OAHUS), and the medium was sterilized in a semi-automatic vertical 
Felisa autoclave for 15 minutes at $121^{\circ} \mathrm{C}$. For the multiplication of shoots, the medium was added with $2.0 \mathrm{mg} \mathrm{l}^{-1}$ of $\mathrm{BA}$ and, for the maintenance of the basal part with roots, with $0.5 \mathrm{mg} \mathrm{^{-1 }}$ of AIA. The incubation temperature was $26^{\circ} \mathrm{C}$, with a photoperiod of $16 \mathrm{~h}$ light and $8 \mathrm{~h}$ darkness, with luminous intensity of $68 \mu \mathrm{mol} \mathrm{m}^{-2} \mathrm{~s}^{-1}$ using white light LED lamps. They were allowed to grow for 30 days.

Rooting tests in the in vitro culture. As the main objective of the study was to generate complete plants, a rooting test was conducted under in vitro conditions. 30 shoots were used to test three doses $0.5,1.0$ and $2.0 \mathrm{mg} \mathrm{l}^{-1}$ of ANA, $\%$ of activated carbon $\left(\right.$ Sigma ${ }^{\circledR}$ ), added to the DCR base medium. We evaluated root formation at day 30 th. The results of this test were taken as negative control for the evaluation of micro- and minigrafts.

Micro- and mini- grafts trials. For the micro-graft trials, the shoots obtained from in vitro multiplication were taken and the apical meristems with approximately $5 \mathrm{~mm}$ were isolated. With the help of a stereoscopic microscope, micro-grafting was done on the base of roots, the entire process was carried out in a laminar flow hood (in vitro manipulation). For the mini-grafts, the shoots generated were allowed to grow to an average length of 3 $\mathrm{cm}$ and were grafted in two-month-old nursery seedlings with an average length of 26.7 $\mathrm{cm}$ (terminal graft was performed). This process is considered ex vitro management since it is not done in the laminar flow hood and there is no strict control of asepsis.

Statistical analysis. All trials were performed under a completely random experimental design with 30 repetitions per treatment. Recorded variables were graft success for both micro and mini, explant length, number of internodes, number of shoots and roots. Two evaluations were done, at 30 and 60 days. As control for complete plants (positive control), data from germinated seeds were taken and 30 shoots were used as negative control in medium supplemented with $0.5,1.0$ and $2.0 \mathrm{mg} \mathrm{l}^{-1}$ of AIA. Analysis of variance was performed with the data obtained, and means comparison was done with Tukey's test (P $\leq$ 0.05). The SAS v9 software was used for data analysis (SAS Institute, 2002).

\section{RESULTS AND DISGUSSION}

The in vitro establishment of Pinus patula was achieved successfully from seeds, taking as a reference the results reported by Castillo et al. (2018) in Pesudotsuga menziesii. A germination of $96 \%$ was obtained in aseptic conditions and only $2.8 \%$ of contamination, so it is considered that the decontamination train was efficient.

The separation of the hypocotyl to be used as initial explant for the multiplication, in DCR medium added with BA, had de result of the formation of de novo shoots with an average of 3.9 shoots per explant, as reported by Arnold and Eriksson (1981) in Pinus contorta or what was observed in Pseudotsuga menziesii by Castillo et al. (2018). Although it is not a high multiplication rage, let us remember that it is exponential to the extent that sub-cultures are carried out.

Concerning the isolated epicotyls to maintain the base and the roots, it was achieved for these to be maintained for a period of 30 days, conserving their vigor in DCR medium with $0.5 \mathrm{mg} \mathrm{l}^{-1}$ of AIA; these served as micro-rootstock or micro-understock, for the micro-grafting process. 
The formation of roots in shoots generated in vitro has been reported in other species such as Pinus massoniana, through the addition of ANA to the culture medium (Wang and Yao, 2019), although a good part of species of the genus Pinus generate a low or null number of roots (Thorpe, 2004). The tests performed with three concentrations of ANA added to the DCR medium showed this response with Pinus patula (Table 1), and therefore in the micro- and mini- grafting tests the seedlings that formed a low number of roots were considered as negative control, and on the other hand, the data of seedlings derived from the in vitro germination as positive control.

Regarding the micro-grafts trials, contrary to what was reported in other species such as Pinus pinea, which reported 43\% of success, and Pinus radiata (Fraga et al., 2002 and Oviedo et al., 2008) which reported successful grafting, growth and development of micro-grafted plants - and to what was expected, it was observed that even with experienced staff every micro-graft took on average 36 minutes, due to the complexity of the process itself and therefore the excessive manipulation time of meristems dissected to be micro-grafted. At the end of the evaluation, low grafting success and oxidation of tissues took place (Table 2).

In the case of mini-grafts (in vitro shoots generated, used as spikes and seedlings produced from seed as rootstock or understock), according to those reported in other species such as Prosopis alba, which through mini-grafts achieved a maximum of $70 \%$ of grasping indicate that the technique for massive production and at the scale of plants can be used (Ewens and Felker, 2003). In this sense, grafting success with high percentage and terminal graft technique was achieved, done in a time of 4 minutes on average, including the cutting, generation of the graft's draw cleft, and protection with union cite. Contamination was not observed and 93.3\% of success was achieved (Table 2 and Figure 1).

Table 1. Effect of three ANA concentrations on the formation of in vitro roots in Pinus patula.

\begin{tabular}{c|c|c}
\hline Trial ANA & Root Length $(\mathbf{m m})$ & Number of Roots \\
\hline Testigo & $12.60 \mathrm{a}$ & $7.03 \mathrm{a}$ \\
\hline 0.5 & $1.56 \mathrm{c}$ & $1.28 \mathrm{~b}$ \\
\hline 1.0 & $2.36 \mathrm{~b}$ & $0.94 \mathrm{bc}$ \\
\hline 2.0 & $1.95 \mathrm{bc}$ & $0.63 \mathrm{c}$ \\
\hline
\end{tabular}

Means with the same letter in columns are statistically equal (Tukey, 0.05). The control was germinated in vitro.

Table 2. Grafting response of micro- and mini-grafts in Pinus patula at 30 days.

\begin{tabular}{c|c|c|c|c}
\hline Trial & Growth Length $\mathbf{~ m m}$ & Performance & Whole Plant & Number of roots \\
\hline Control + & $33.60 \mathrm{c}$ & N/A & $\mathrm{Si}$ & $21.03 \mathrm{a}$ \\
\hline Control - & 6.56 & N/A & $\mathrm{No}$ & $1.28 \mathrm{c}$ \\
\hline Micro graft & $2.36 \mathrm{~b}$ & 3.0 & $\mathrm{Si}$ & $1.94 \mathrm{~b}$ \\
\hline Mini graft & $26.05 \mathrm{~b}$ & 28.0 & $\mathrm{Si}$ & $18.63 \mathrm{ab}$ \\
\hline
\end{tabular}

Means with the same letter in columns are statistically equal (Tukey, 0.05), the Control + correspond to nursery seedlings, the control - corresponds to shoots obtained in vitro in rooting medium. 

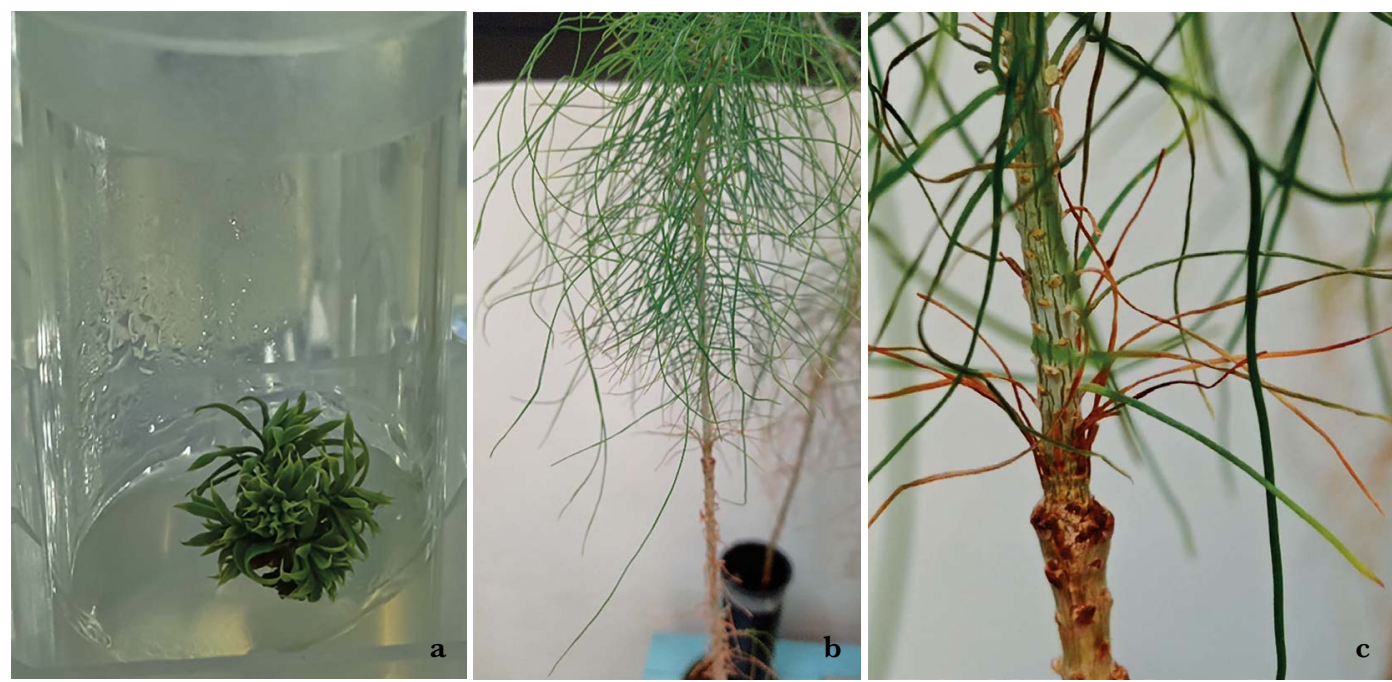

Figure 1. a) In vitro development of Pinus patula shoots at 30 days in DCR medium added with BA, b) Grafting success and development of mini-graft at 30 days, c) Union of rootstock and graft generated in vitro of Pinus patula.

\section{GONGLUSIONS}

The establishment of Pinus patula was achieved in in vitro conditions. Germination was obtained from seeds in DCR medium, and a multiplication of shoots in this medium added with $2.0 \mathrm{mg} \mathrm{l}^{-1}$ of BA.

The management of micro-grafts for Pinus patula showed a high degree of complexity in the isolation and management of meristems and therefore, in the process of micro-grafting, where there were oxidation problems and low success.

The technique of mini-grafts is a viable option for Pinus patula, of simple management with an acceptable grafting success, growth and development of mini-grafts.

\section{ACKNOWLEDGEMENTS}

The authors thank the CONACYT-CONAFOR 2017-2-291322 fund for financing to carry out this research.

\section{REFERENGES}

Álvarez Correa, C. C. (2020). Evaluación de la eficacia de los métodos de mini injertos hendidura, t invertida y yema terminal en la propagación de plantas de naranja valencia (Citrus sinensis (L.) Osbeck.).

Arnold, S. V., \& Eriksson, T. (1981). In vitro studies of adventitious shoot formation in Pinus contorta. Canadian Journal of Botany, 59(5), 870-874.

Atree, S. M., \& Fowke, L. C. (1991). Micropropagation through somatic embryogenesis in conifers. In HighTech and Micropropagation I (pp. 53-70). Springer, Berlin, Heidelberg.

Castillo-Martínez, C. R., García-Campusano, F., Vallejo-Reyna, M. A., \& Reyes-Martínez, I. (2018). Mutagenesis of in vitro material from Pseudotsuga menziesii and obtaining mutant lines. Agroproductividad, 11(12), 33-39.

Cortizo, M., Alonso, P., Fernández, B., Rodríguez, A., Centeno, M. L., \& Ordás, R. J. (2004). Micrografting of mature stone pine (Pinus pinea L.) trees. Annals of Forest Science, 61(8), 843-845.

Ewens, M., \& Felker, P. (2003). The potential of mini-grafting for large-scale production of Prosopis alba clones. Journal of Arid Environments, 55(2), 379-387.

Fraga, M. F., Cañal, M. J., Aragonés, A., \& Rodríguez, R. (2002). Factors involved in Pinus radiata D. Don. micrografting. Annals of Forest Science, 59(2), 155-161. 
Grossnickle, S. C., Cyr, D., \& Polonenko, D. R. (1996). Somatic embryogenesis tissue culture for the propagation of conifer seedlings: A technology comes of age. Tree Planters Notes, 47, 48-57.

Gupta, P. K., \& Durzan, D. J. (1985). Shoot multiplication from mature trees of Douglas-fir (Pseudotsuga menziesii) and sugar pine (Pinus lambertiana). Plant Cell Reports, 4(4), 177-179.

Montalbán, I. A., De Diego, N., Igartua, E. A., Setién, A., \& Moncaleán, P. (2011). A combined pathway of somatic embryogenesis and organogenesis to regenerate radiata pine plants. Plant Biotechnology Reports, $5(2), 177$

Oviedo, M. E. M., Castro, M. G. V., Sánchez-Olate, M. E., Sáez, K. L., Fernández, R. R., \& Leal, D. G. R. (2008). Reactivación de material vegetal élite de Pinus radiata D. Don. mediante microinjerto in vitro. Interciencia, 33(1), 66-70.

Prehn, D., Serrano, C., Mercado, A., Stange, C., Barrales, L., \& Arce-Johnson, P. (2003). Regeneration of whole plants from apical meristems of Pinus radiata. Plant Cell, Tissue and Organ Culture, 73(1), 91-94.

SAS Institute. 2002. User's Guide of SAS (Statistical Analysis System). SAS Institute Inc. Cary, N. C. USA. $550 \mathrm{p}$.

Thorpe, T. A. (2004). Turning point article to root or not to root that is the question: reflections of a developmental plant physiologist. In Vitro Cellular \& Developmental Biology-Plant, 40(2), 128-142.

Wang, Y., \& Yao, R. (2019). Optimization of rhizogenesis for in vitro shoot culture of Pinus massoniana Lamb. Journal of Forestry Research, 1-7. 